\title{
PENGUJIAN RULE PADA SISTEM PAKAR PENANGANAN CEDERA OLAHRAGA BOLA BASKET
}

\author{
Diki Arisandi \\ Program Studi Teknik Informatika, Fakultas Teknik, Universitas Abdurrab Pekanbaru \\ Jalan Riau Ujung No.73 Pekanbaru \\ E-Mail :diki@univrab.ac.id
}

\begin{abstract}
ABSTRAK
Sistem pakar merupakan sebuah sistem yang dibuat dengan menggunakan komputer yang bertujuan untuk meniru para pakar dalam menyelesaikan masalah. Sistem pakar ini dibangun untuk menangani permasalahan cedera pada olahraga bola basket, termasuk bagaimana pengobatannnya. Sebelum digunakan, sistem pakar harus diuji terlebih dahulu agar tidak terjadi kesalahan pada saat digunakan. Pengujian menggunakan metode black-box, yang berarti menguji keluaran sistem berdasrkan masukan. Selain itu, rule dan inferensi pada sistem pakar ini juga diuji agar setiap tahap konsultasi menghasilkan solusi yang sesuai dengan pengetahuan yang dimiliki para pakar. Setelah melalui proses pengujian, diharapkan sistem pakar ini dapat digunakan oleh para pakar sendiri maupun pengguna lainnya dalam mengatasi masalah cedera pada olahraga bola basket.
\end{abstract}

Kata Kunci: bola basket, cedera, inferensi, rule, sistem pakar.

\begin{abstract}
An expert system is a system created by using a computer that aims to imitate the experts in solving the problem. This expert system built to handle the problems of basketball injury, including how to treat it. Before it used, the expert system must be tested beforehand to avoid mistakes when in use. Tests was using black-box method, which means testing system output based on those inputs. otherwise, the rule and inference in expert systems had also been tested so that every stage of the consultation results in solutions that correspond to the expert's expertise. After through the testing process, the expert system can be used by the experts themselves and other users to overcome basketball injury.
\end{abstract}

keywords: basketball, injury, inference, rule, expert system.

\section{PENDAHULUAN}

Sistem pakar diwujudkan kedalam program komputer yang dapat meniru penalaran dan pemecahan masalah dari seorang ahli manusia (Deborah, 2008). Lewat pengalaman dan pengetahuan yang dimilikinya, seorang pakar mengembangkan kemampuan yang membuatnya dapat memecahkan permasalahan dengan hasil yang baik dan efisien. Program sistem pakar dibuat berdasarkan suatu himpunan aturan (rule) yang mampu menganalisis informasi mengenai suatu masalah spesifik serta analisis matematis dari masalah tersebut dan memanfaatkan kemampuan penalaran (reasoning) untuk mencapai suatu kesimpulan.

Salah satu penerapan sistem pakar yaitu pada bidang olahraga bola basket. Sistem pakar yang bekerja berdasarkan pengalaman dan penalaran manusia khususnya pakar atau ahli yang dapat menangani kasus cedera olahraga bola basket, dalam hal ini Fisioterapis atau Dokter. Sehingga berdasarkan pengalaman para pakar dan dipadukan dengan program komputer dapat menghasilkan sebuah sistem pakar yang bisa menangani kasus cedera pada olahraga ini.

Olahraga basket merupakan jenis olahraga yang melibatkan banyak anggota 
tubuh mulai dari bahu, tangan, pinggang, hingga kaki secara bersamaan. Hal ini yang menyebabkan anggota tubuh manapun mempunyai resiko cedera. Cedera yang dialami dapat menjadi lebih parah apabila pemain basket tersebut suka memainkan free-style basketball yang lebih memaksa anggota tubuh untuk bekerja lebih keras sehingga resiko cedera semakin besar.

Sistem pakar yang telah dibangun memiliki rule dan hasil yang dapat digunakan oleh pengguna untuk mengetahui permasalahan cedera yang dialami ketika melakukan aktivitas olahraga bola basket. Namun sebelum sistem pakar ini digunakan, perlu dilakukan pengujian agar dapat digunakan oleh pengguna yang membutuhkan dan tidak mengalami masalah / bug terutama pada saat penelusuran rule dan hasil.

Sehingga, dengan dilakukan pengujian ini, sistem pakar yang digunakan oleh pengguna tidak mengalami kesalahan penelusuran dan kesalahan pada menampilkan solusi yang dapat ditempuh oleh pengguna dalam menangani cedera olahraga bola basket. Karena dikhawatirkan jika terjadi kesalahan pada saat penelusuran maupun mengeluarkan solusi, dikhawatirkan akan terjadi salah tindakan yang akan mengakibatkan cedera yang dialami bertambah parah.

\section{Rumusan Masalah}

Berdasarkan pada latar belakang masalah yang telah dijelaskan sebelumnya, maka permasalahan pokok yang dibahas pada penelitian ini adalah bagaimana melakukan pengujian rule pada sistem pakar penanganan cedera olahraga bola basket?

\section{Batasan Masalah}

Pada pembahasan dalam pengujian sistem pakar penanganan cedera olahraga bola basket ini, batasan masalah-masalah difokuskan sebagai berikut:

1. Pengujian rule untuk setiap regio atau area tubuh pada saat penelusuran gejala cedera yang dialami

2. Pengujian hasil penanganan cedera berdasarkan penelusuran yang telah disusun pada rule

3. Pencocokan output sistem yang berupa solusi penanganan cedera dengan pengalaman dan pengetahuan para pakar.

\section{Tujuan}

Adapun tujuan penelitian yang akan dicapai dalam penulisan ini adalah sebagai berikut:

1. Menguji setiap rule pada setiap regio yang ada pada sistem pakar ini

2. Menguji hasil penanganan cedera berdasarkan penelusuran yang telah disusun pada rule

3. Mencocokkan output sistem yang berupa solusi penanganan cedera dengan pengalaman dan pengetahuan para pakar.

\section{Manfaat}

Manfaat yang didapat dari penelitian ini adalah:

1. Dapat mengetahui kesalahan pada sisi rule atau hasil pada sistem pakar ini.

2. Mengetahui jika ada perbedaan penelusuran antara rule dan hasil pada sistem pakar ini.

3. Dapat menghasilkan sebuah sistem yang siap digunakan jika sistem pakar ini telah melewati proses pengujian. 


\section{Sistem pakar}

Sistem pakar (Expert System) adalah sebuah sistem yang menggunakan pengetahuan manusia dimana pengetahuan tersebut dimasukkan kedalam sebuah komputer dan kemudian digunakan untuk menyelesaikan masalah-masalah yang biasanya membutuhkan kepakaran atau keahlian manusia (Turban, 2001). Dengan sistem pakar ini, orang awam pun dapat menyelesaikan masalah yang cukup rumit yang sebenarnya hanya dapat dilakukan oleh para pakar.

Sistem pakar terdiri dari dua komponen utama: basis pengetahuan dan mesin inferensi (Weiming dan Keitirou, 2000) Pengguna menyampaikan fakta atau informasi untuk sistem pakar dan kemudian menerima saran dari pakar atau jawaban ahlinya. Bagian dalam sistem pakar terdiri dari dua komponen utama, yaitu knowledgebase yang berisi knowledge dan mesin inferesi yang menggambarkan kesimpulan. Kesimpulan tersebut merupakan respons dari sistem pakar atas permintaan pengguna. Gambaran antara pengguna, basis pengetahuan dan mesin inferensi dapat terlihat pada gambar berikut:

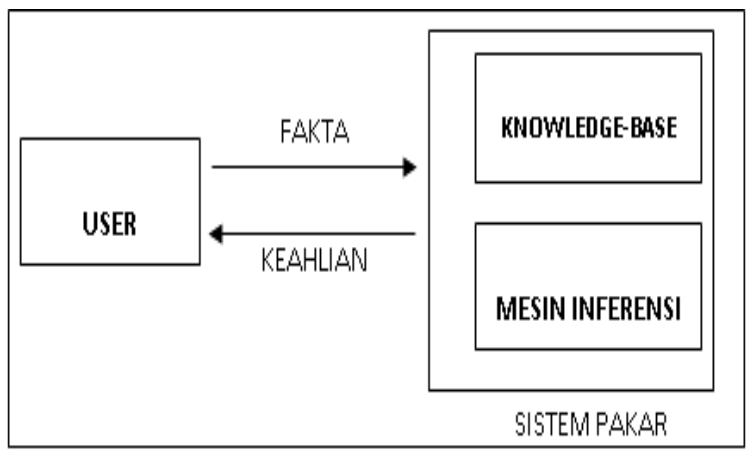

Gambar 1. Konsep Dasar Sistem Pakar

Suatu knowledge dari sistem pakar bersifat khusus untuk satu domain masalah saja. Domain masalah adalah bidang atau ruang lingkup yang khusus, seperti kedokteran, keuangan, bisnis, pertanian, pendidikan dan lain-lain. Sistem pakar menyerupai kepakaran seseorang yang secara umum dirancang unutk menjadi pakar dalam satu domain saja.

Secara garis besar, banyak manfaat yang dapat diambil dengan adanya sistem pakar, antara lain:

a. Memungkinkan orang awam bisa mengerjakan pekerjaan para ahli.

b. Bisa melakukan proses secara berulang secara otomatis.

c. Menyimpan keahlian dan pengetahuan para pakar

d. Meningkatkan kapabilitas dalam penyelesaian masalah

e. Menghemat waktu dalam pengambilan keputusan.

Sistem Pakar dibagi menjadi 2 bagian utama: lingkungan pengembangan (development environment) dan lingkungan konsultasi (consultation runtime environment). Lingkungan pengembangan digunakan oleh Pembangun Sistem Pakar (Expert System builder) untuk membangun komponen dan untuk membawa pengetahuan ke dalam knowledge-base. Sedangkan Lingkungan konsultasi digunakan oleh orang yang bukan ahli untuk mendapatkan pengetahuan dan saran setara pakar. Komponen-komponen sistem pakar dalam kedua bagian tersebut dapat dilihat dalam gambar 2. 


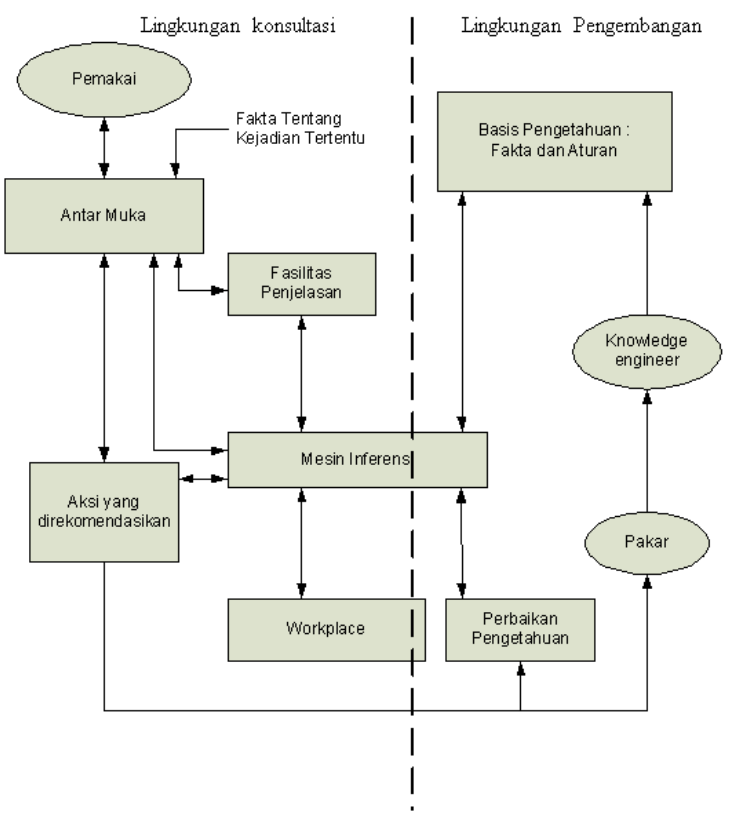

Gambar 2. Bagian Pada Sistem Pakar

\section{Bola Basket}

Bola basket adalah olahraga bola berkelompok yang terdiri atas dua tim beranggotakan masing-masing lima orang yang saling bertanding mencetak poin dengan memasukkan bola ke dalam keranjang lawan. Basket dianggap sebagai olahraga unik karena diciptakan secara tidak sengaja oleh seorang guru olahraga.

Pada tahun 1891, Dr. James naismith, seorang guru Olahraga asal Kanada yang mengajar di sebuah perguruan tinggi untuk para siswa profesional di YMCA (sebuah wadah pemuda umat Kristen) di Springfield, Massachusetts, harus membuat suatu permainan di ruang tertutup untuk mengisi waktu para siswa pada masa liburan musim dingin di New England. Terinspirasi dari permainan yang pernah ia mainkan saat kecil di Ontario, naismith menciptakan permainan yang sekarang dikenal sebagai bola basket pada 15 Desember 1891.

\section{METODE}

Sistem yang dibangun juga harus harus diuji. Tujuannya agar dapat menghilangkan kesalahan pada saat sistem dijalankan atau digunakan oleh user. Pada penelitian ini, sistem diuji menggunakan pengujian blackbox. "The black box specifies the behavior of a system or a part of a system. The system (or part) responds to specific stimuli (events) by applying a set of transition rules that map the stimulus into a response" (Pressman, 2001).

Langkah - langkah Pengujian dilakukan secara bottom-up, yaitu dimulai dari modul yang paling rendah hingga modul yang paling tinggi. Pada sistem pakar pengobatan cedera olahraga basket terdapat beberapa modul, yaitu modul user, modul penerimaan pengetahuan dan modul konsultasi. Setiap modul yang ada diuji secara terpisah dan dimulai dari fungsi tiaptiap modul yang ada. Setelah setiap modul diuji secara terpisah, pengujian berikutnya adalah dengan menggabungkan modulmudul yang ada dan mengujinya kembali. Dan untuk pengujian terakhir, dilakukan pengujian data dengan beberapa skenario yang mungkin dapat terjadi. Sehingga dari skenario tersebut dapat diketahui output yang dihasilkan dari sistem yang dibangun.

\section{HASIL}

\section{Gambaran Sistem Secara Global}

Secara global, sistem pakar yang diuji memiliki gambaran sebagai berikut:

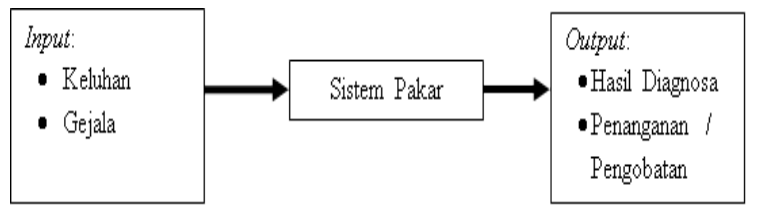

Gambar 3.Gambaran Sistem Secara Global 
Pada gambar 3 terlihat bahwa sistem bekerja jika ada masukan / input dari user yang berupa keluhan dan gejala yang dipilih pada interface. Setelah itu, sistem pakar bekerja menelusuri berdasarkan rule yang digerakkan oleh mesin inferensi. Setelah seluruh kondisi pada rule terpenuhi, maka mesin inferensi tersebut akan mencari hasil / output yang berupa hasil diagnosa dan penanganan atau pengobatan yang dapat dilakukan.

\section{Gambaran Basis Pengetahuan}

Pada struktur basis pengetahuan, bagan yang dapat dilihat dipecah berdasarkan regio. Setelah itu untuk dapat menghasilkan suatu konklusi dan aturan terapi, konklusi dan aturan terapi tersebut terlebih dahulu dirunut berdasarkan kondisi yang berupa gejala yang dialami oleh penderita cedera olahraga basket. Jadi, penggambaran secara keseluruhan mengenai struktur basis pengetahuan dapat dilihat pada gambar 4.

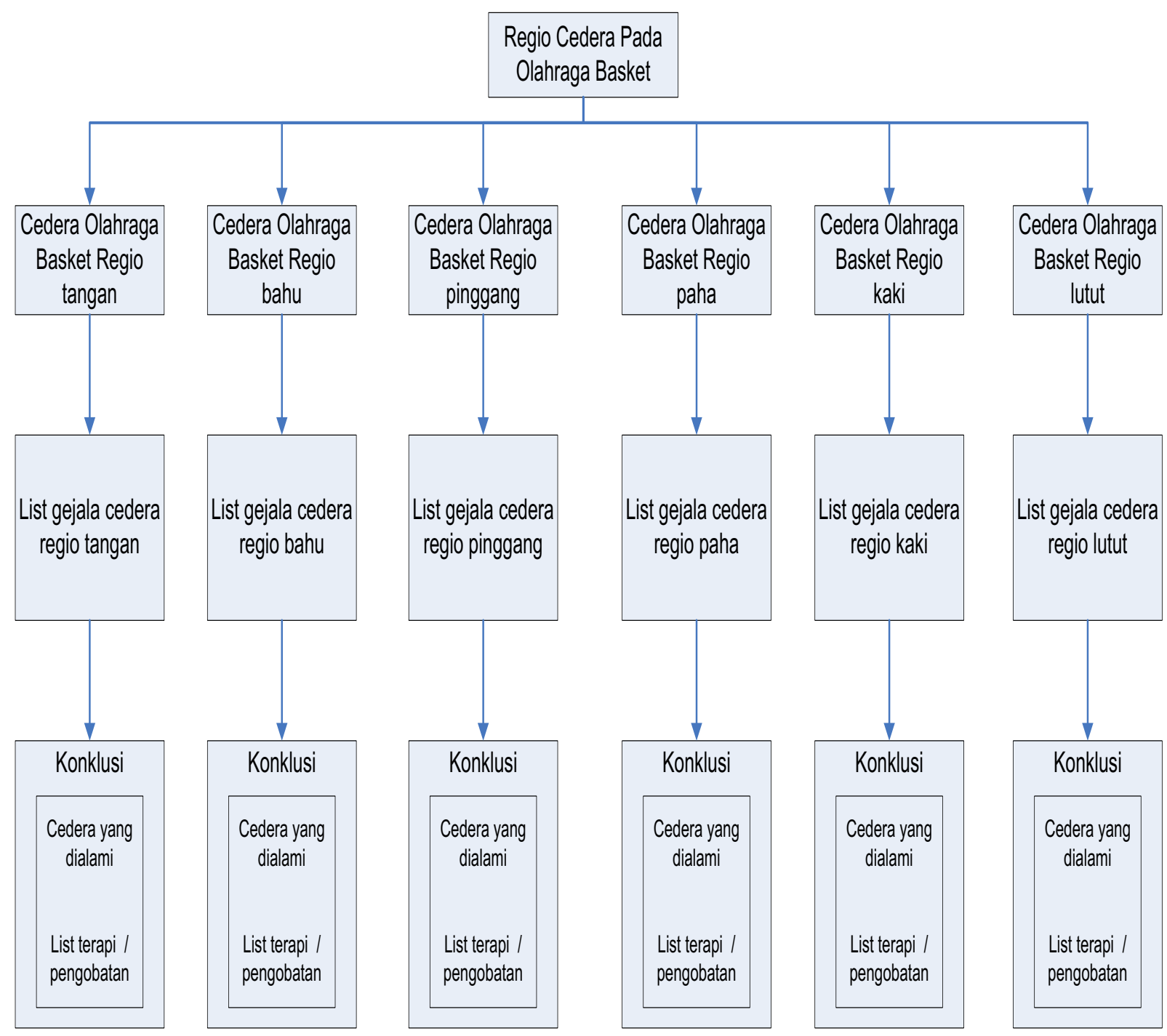

Gambar 5. Struktur Basis Pengetahuan Secara Keseluruhan 
Dari struktur basis pengetahuan secara keseluruhan, maka dapat diketahui penggambaran struktur basis pengetahuan berdasarkan regio yang ada. Setelah itu, maka dibentuklah rule dari struktur basis pengetahuan yang ada dengan basis If dan Then. Adapun formulasi yang terlihat pada sistem pakar ini adalah sebagai berikut:

\author{
Rule: \\ IF [Premis 1] \\ AND [Premis 2] \\ AND [Premis 3] \\ AND [Premis n] \\ THEN [Konklusi]
}

Dari bentuk tersebut, maka rule untuk mendiagnosa gejala cedera olahraga basket yang terlihat dapat dilihat pada tabel berikut:

Tabel 1. Tabel Rule Yang Terbentuk

\begin{tabular}{cl}
\hline No & \multicolumn{1}{c}{ Aturan } \\
\hline 1 & IF regio tangan (R01) \\
& AND posisi tangan tidak bisa \\
& diluruskan (R011) \\
& AND disertai nyeri pada \\
& pergelangan tangan (R0111) \\
& AND Pergelangan tangan tampak \\
& merah \& terlihat menonjol \\
& (R01111) \\
& THEN Colee's Fracture (C0001) \\
\hline $\mathbf{2}$ & IF regio tangan (R01) \\
& AND Kesemutan atau mati rasa di \\
& jari atau tangan, terutama ibu jari \\
& dan jari telunjuk (R012) \\
& AND Nyeri memanjang dari \\
& pergelangan tangan sampai lengan \\
& dan bahu atau ke dalam telapak \\
& tangan atau jari (R0121) \\
& AND Tangan terasa lemah, susah \\
\hline
\end{tabular}

mengepal, dan kecenderungan untuk menjatuhkan benda (R01211) THEN Carpal tunel syndrome (C0002)

3 IF regio tangan (R01)

AND Jempol susah untuk dilipat dan terasa sakit bila digerakkan (R013)

AND munculnya rasa nyeri pada lengan bawah pada sisi ibu jari, dekat dengan pergelangan tangan (R0131)

AND terasa nyeri pada saat menggenggam sesuatu (R01311)

AND kemerahan pada ibu jari (R013111)

THEN De quervain's tenosynovitis syndrome (C0003)

4 IF regio tangan (R01)

AND Nyeri pada sendi diujung jari pasca benturan (R014)

AND Tampak bengkak dan kemerahan pada sendi jari (R0141) AND Ujung jari tidak bisa diluruskan (R01411)

THEN Cedera Mallet finger
(C0004)

5 IF regio bahu (R02)

AND Nyeri diantara lengan dan bahu, terutama pada saat mengangkat tangan hingga keatas kepala. (R021)

AND Bahu terasa lemah (R0211)

AND Terasa sakit dan tidak kuat sewaktu mengangkat benda (bola) \& tidak mampu mengangkat tangan lebih dari 90 derajat abduksi (gerakan menjauhi badan) (R02111) THEN Cedera Rotator cuff (C0005)

6 IF regio pinggang (R03) 
AND Nyeri pada bagian pinggang (R031)

AND Terasa sakit pada saat berdiri atau meluruskan pinggang (R0311)

AND Terasa sakit pada saat membungkuk atau mengangkat benda jatuh / benda dilantai. (R03111)

THEN Back Strain (C0006)

7 IF regio paha (R04)

AND Nyeri di paha belakang yang berlangsung tiba-tiba, ketika beraktivitas (R041)

AND Bengkak dan terasa lunak dalam beberapa jam setelah cedera terjadi (R0411)

AND Kaki bagian belakang lebam / berubah warna (R04111)

AND Otot melemah / kaki tidak mampu menahan beban (R041111)

THEN Cedera otot hamstring (C0007)

8 IF regio paha (R04)

AND Nyeri di paha bagian depan (R041)

AND Otot terasa kaku (R0412)

AND Tampak memar, bengkak dan kemerahan pada bagian depan (R04121)

AND Otot melemah / kaki tidak mampu menahan beban (R041211)

THEN Quadricep strain (C0008)
(R0511)

AND Nyeri tajam pada kaki (R05111)

AND pada saat berjalan, pola jalan abnormal karena tumpuan kaki pada saat berjalan bukan bertumpu pada tumit (heel straigth hilang) (R051111)

THEN Sprain pada engkel kaki (C0009)

10 IF regio kaki (R05)

AND Nyeri yang bermula di tumit dan menyebar ke arah jari-jari kaki (R052)

AND Nyeri muncul ketika bangun tidur, berdiri terlalu lama atau bangun dari posisi duduk / istirahat (R0521)

AND Tumit seperti ditusuk-tusuk (R05211)

AND Terasa pincang, atau memilih berjalan dengan berjinjit (R052111)

AND Bengkak dan kemerahan ringan pada tumit (R0521111)

AND Kaki dan tumit terasa lunak jika sedikit ditekan maupun pada saat menggerakkan jari-jari kaki. (R05211111) THEN Plantar fasciitis (C0010)

11 IF regio kaki (R05)

AND Nyeri pada tulang tumit dikarenakan benturan / trauma yang berulang-ulang sewaktu berolahraga (R053)

AND Nyeri muncul ketika bangun tidur, berdiri terlalu lama atau bangun dari posisi duduk (R0531)

AND Tulang tumit seperti ditusuktusuk \& sakit bila mulai menapak atau berjalan (R05311)

AND Terasa pincang, atau memilih berjalan dengan berjinjit (R053111) THEN Calcaneus Spur (C0011)

12 IF regio kaki (R05)

AND Bengkak pada lateral kaki (R051)

AND Kemerahan pada lateral kaki 
(R0511)

AND Nyeri tajam pada kaki (R05111)

AND Terasa nyeri yang berkepanjangan setelah menderita sprain engkel (R051121)

AND Engkel kaki terasa lemah (R0511211)

AND Rasa nyeri biasanya terasa pada bagian depan / belakan engkel kaki (R05112111) THEN Impingement ankle (C0012)

13 IF regio kaki (R05)

AND Bengkak pada lateral kaki (R051)

AND Kemerahan pada lateral kaki (R0511)

AND Nyeri tajam pada kaki (R05111)

AND Nyeri pada saat berjalan (R051131)

AND Kaki menjadi lemas, dikarenakan sudah pernah sprain sebelumnya / keseleo berulangulang (R0511311)

THEN Ankle instability (C0013)

14 IF regio kaki (R05)

AND Nyeri di bagian depan kaki (R054)

AND Daerah di sekitar tulang dibagian depan kaki mengalami pembengkakan (R0541)

AND kulit di sekitar tulang dibagian depan kaki berubah warna menjadi

kemerahan (R05411)

AND Terasa nyeri apabila kaki menyentuh lantai walaupun sedikit (R054111)

THEN Fraktur Metatarsal (C0014)

15 IF regio lutut (R06)

AND Rasa nyeri diantara tempurung lutut dan tulang kering (R062)

AND Rasa nyeri yang dirasakan makin hebat apabila melakukan aktivitas (berjalan / berlari) (R0621)

THEN Cedera Jumper's knee /

Patella Tendinitis (C0016)

\begin{tabular}{ll}
\hline $\mathbf{N}$ & Aturan \\
$\mathbf{0}$ & \\
\hline 16 & IF regio lutut (R06)
\end{tabular}

AND Nyeri tajam sewaktu jinjit (R063)

AND Nyeri secara bertahap dan memburuk dari waktu ke waktu di bagian belakang kaki dan di atas tumit teutama pada saat latihan intens seperti berlari (R0631)

AND Kaku otot, terutama di pagi hari namun membaik dengan aktivitas ringan (R06311)

AND Pembengkakan ringan atau benjolan pada tendon Achilles / otot bagian atas tumit (R063111)

AND Suara berderak atau berderit ketika menyentuh atau menggerakkan tendon Achilles (R0631111)

AND Lemahan pada kaki bagian bawah (R06311111)

THEN Cedera Tendinitis achilles / tendon achilles (C0017)

17 IF regio lutut (R06)

AND Nyeri pada daerah antara lutut dan paha waktu ditekuk atau diluruskan (R061)

AND Bengkak pada lutut (R0611)

AND Terkunci pada saat meluruskan atau menekuk (R06111)

AND Serasa ada yang bergerakgerak di dalam sendi (R061111)

THEN Cedera Meniscus (C0015)

18 IF regio lutut (R06)

AND Nyeri tajam sewaktu jinjit (R063)

AND kejang pada otot betis (R0632)

AND nyeri hebat pada betis (R06321)

AND Sakit jika digerakkan (R063211)

THEN Kram pada betis / ligamen 


\begin{tabular}{ll}
\hline (C0018) \\
\hline 19 IF regio lutut (R06) \\
AND Rasa sakit di bagian luar \\
lutut, tepat di atas sendi lutut (R064) \\
\hline $\begin{array}{l}\text { AND kesulitan melakukan gerakan } \\
\text { dorso fleksi engkel / }\end{array}$ susah \\
mengangkat pergelangan kaki \\
keatas dan Lutut tidak bisa \\
diluruskan sepenuhnya (R0641) \\
AND Bengkak dan kaku pada \\
bagian yang merasakan sakit \\
(R06411) \\
AND Memerah dan terasa hangat \\
ketika disentuh (R064111) \\
AND Terasa lemah atau tidak stabil \\
(R0641111) \\
AND Terdengar suara seperti \\
berderak-derak \\
\hline
\end{tabular}

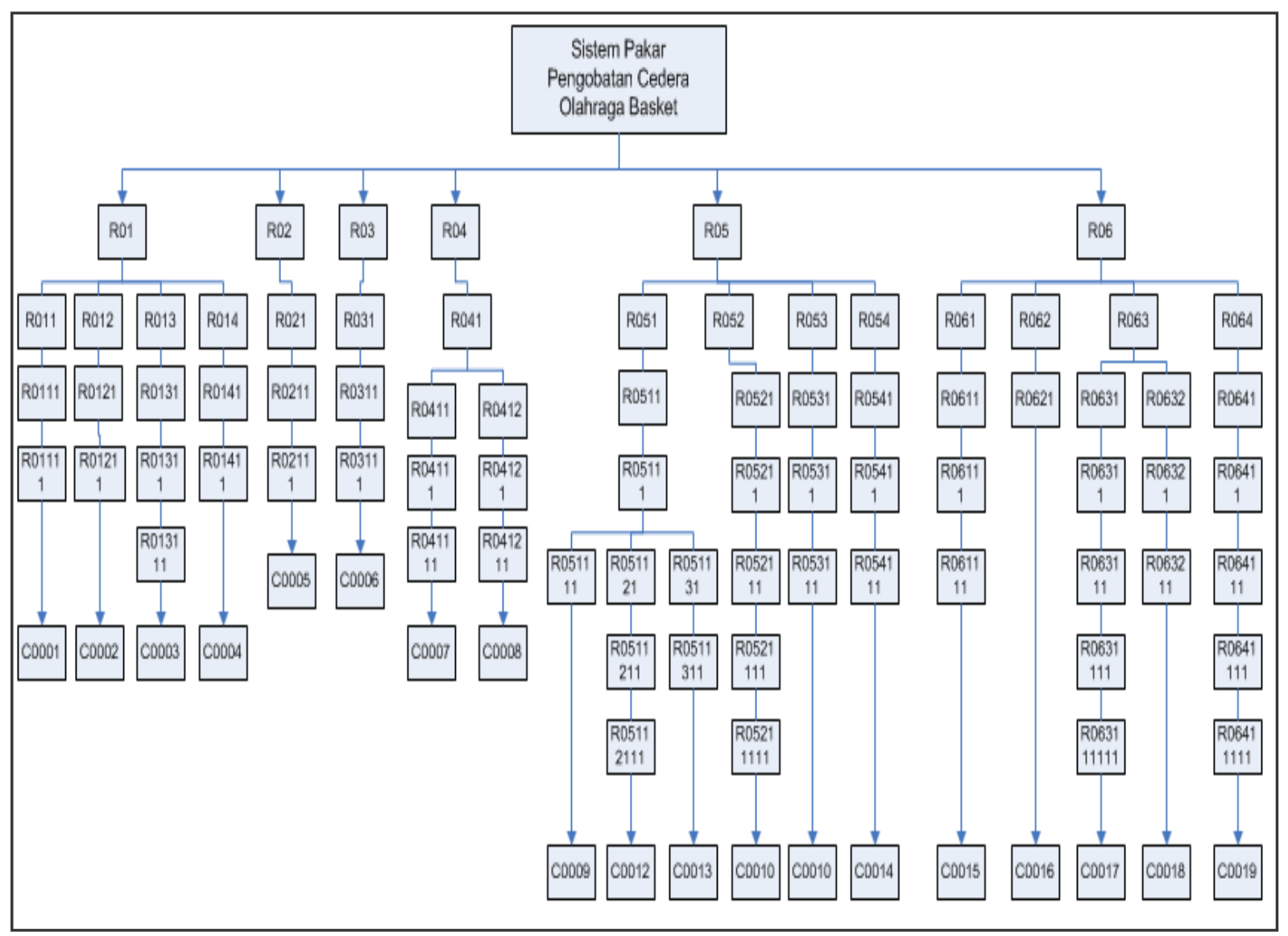

\section{Pengujian Rule Pada Sistem Pakar}

Dari pohon keputusan yang ada pada gambar 6, maka dilakukan pengujian rule pada sistem dan
(R06411111)

THEN Iliotibial band syndrome (C0019)

Pada tabel 1 dapat dilihat bahwa sistem pakar ini menelusuri berdasarkan kondisi-kondisi yang ada. Jika semua kondisi terpenuhi, maka sistem pakar akan menghasilkan konklusi atau hasil. Secara garis besar, penelusuran tersebut dapat dilihat pada gambar diagram pohon keputusan sebagai berikut: 
Tabel 2. Hasil Pengujian Sistem

\begin{tabular}{|c|c|c|c|c|}
\hline $\mathbf{0}^{\mathbf{N}}$ & Kasus & Pengamatan Inferensi & Hasil & Ket. \\
\hline 1 & $\begin{array}{l}\text { Cedera Regio } \\
\text { tangan }\end{array}$ & $\begin{array}{llr}\mathrm{R} 01 \rightarrow & \mathrm{R} 011 \rightarrow & \mathrm{R} 0111 \rightarrow \\
\mathrm{R} 01111 & \text { (empat } & \text { kali } \\
\text { penelusuran) } & & \end{array}$ & $\begin{array}{l}\text { C0001: } \\
\text { Colee's Fracture }+ \\
\text { Terapi pengobatan }\end{array}$ & Cocok \\
\hline 2 & $\begin{array}{l}\text { Cedera Regio } \\
\text { tangan }\end{array}$ & $\begin{array}{l}\mathrm{R} 01 \rightarrow \mathrm{R} 012 \rightarrow \\
\text { R01211 } \\
\begin{array}{l}\text { (empat } \\
\text { penelusuran) }\end{array}\end{array}$ & $\begin{array}{l}\text { C0002: } \\
\text { Carpal tunel syndrome } \\
+ \text { Terapi pengobatan }\end{array}$ & Cocok \\
\hline 3 & $\begin{array}{l}\text { Cedera Regio } \\
\text { tangan }\end{array}$ & $\begin{array}{l}\text { R01 } \rightarrow \text { R013 } \rightarrow \text { R0131 } \rightarrow \\
\text { R01311 } \rightarrow \text { R013111 (lima kali } \\
\text { penelusuran) }\end{array}$ & $\begin{array}{l}\text { C0003: } \\
\text { De quervain's } \\
\text { tenosynovitis syndrome } \\
+ \text { Terapi pengobatan }\end{array}$ & Cocok \\
\hline 4 & $\begin{array}{l}\text { Cedera Regio } \\
\text { tangan }\end{array}$ & 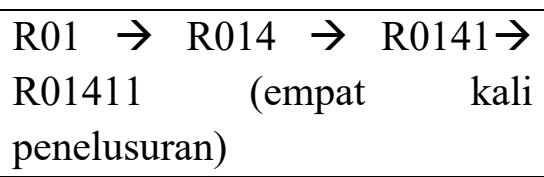 & $\begin{array}{l}\text { C0004: } \\
\text { Cedera Mallet finger }+ \\
\text { Terapi pengobatan }\end{array}$ & Cocok \\
\hline 5 & $\begin{array}{l}\text { Cedera Regio } \\
\text { bahu }\end{array}$ & $\begin{array}{l}\mathrm{R} 02 \rightarrow \mathrm{R} 021 \rightarrow \mathrm{R} 0211 \rightarrow \\
\text { R02111 } \begin{array}{l}\text { (empat } \\
\text { penelusuran) }\end{array}\end{array}$ & $\begin{array}{l}\text { C0005: } \\
\text { Cedera Rotator cuff }+ \\
\text { Terapi pengobatan }\end{array}$ & Cocok \\
\hline 6 & $\begin{array}{l}\text { Cedera Regio } \\
\text { pinggang }\end{array}$ & $\begin{array}{l}\mathrm{R} 03 \rightarrow \mathrm{R} 031 \rightarrow \mathrm{R} 0311 \rightarrow \\
\begin{array}{l}\text { R03111 } \\
\text { penelusuran) }\end{array}\end{array}$ & $\begin{array}{l}\text { C0006: } \\
\text { Back Strain }+ \text { Terapi } \\
\text { pengobatan }\end{array}$ & Cocok \\
\hline 7 & $\begin{array}{l}\text { Cedera Regio } \\
\text { paha }\end{array}$ & $\begin{array}{l}\mathrm{R} 04 \rightarrow \mathrm{R} 041 \rightarrow \mathrm{R} 0411 \rightarrow \\
\mathrm{R} 04111 \rightarrow \mathrm{R} 041111 \text { (lima } \\
\text { kali penelusuran) }\end{array}$ & $\begin{array}{l}\text { C0007: } \\
\text { Cedera otot hamstring } \\
+ \text { Terapi pengobatan }\end{array}$ & Cocok \\
\hline 8 & $\begin{array}{l}\text { Cedera Regio } \\
\text { paha }\end{array}$ & $\begin{array}{l}\mathrm{R} 04 \rightarrow \mathrm{R} 041 \rightarrow \mathrm{R} 0412 \rightarrow \\
\mathrm{R} 04121 \rightarrow \mathrm{R} 041211 \text { (lima } \\
\text { kali penelusuran) }\end{array}$ & $\begin{array}{l}\text { C0008: } \\
\text { Quadricep strain } \quad+ \\
\text { Terapi pengobatan }\end{array}$ & Cocok \\
\hline 9 & $\begin{array}{l}\text { Cedera Regio } \\
\text { kaki }\end{array}$ & $\begin{array}{l}\text { R05 } \rightarrow \text { R051 } \rightarrow \text { R0511 } \rightarrow \\
\text { R05111 } \rightarrow \text { R051111 (lima kali } \\
\text { penelusuran) }\end{array}$ & $\begin{array}{l}\text { C0009: } \\
\text { Sprain pada engkel kaki } \\
+ \text { Terapi pengobatan }\end{array}$ & Cocok \\
\hline 10 & $\begin{array}{l}\text { Cedera Regio } \\
\text { kaki }\end{array}$ & $\begin{array}{l}\mathrm{R} 05 \rightarrow \mathrm{R} 052 \rightarrow \mathrm{R} 051 \rightarrow \\
\mathrm{R} 0511 \rightarrow \mathrm{R} 05111 \rightarrow \mathrm{R} 051111 \\
\rightarrow \quad \mathrm{R} 0511111 \quad \text { (tujuh kali } \\
\text { penelusuran) }\end{array}$ & $\begin{array}{l}\text { C0010: } \\
\text { Plantar fasciitis } \\
\text { Terapi pengobatan }\end{array}$ & Cocok \\
\hline 11 & sio & $\mathrm{R} 05 \rightarrow \mathrm{R} 053 \rightarrow \mathrm{R} 051 \rightarrow$ & C0011: Calcaneus Spur & cok \\
\hline
\end{tabular}


RABIT : Jurnal Teknologi dan Sistem Informasi Univrab

Volume 1 No. 2 | Juli 2016 : 98-104

kaki

R0511 $\rightarrow$ R05111 (lima kali + Terapi pengobatan penelusuran)

\begin{tabular}{|c|c|c|c|c|}
\hline No & Kasus & Pengamatan Inferensi & Hasil & Ket. \\
\hline 12 & $\begin{array}{l}\text { Cedera Regio } \\
\text { kaki }\end{array}$ & $\begin{array}{l}\mathrm{R} 05 \rightarrow \mathrm{R} 051 \rightarrow \mathrm{R} 0511 \rightarrow \\
\mathrm{R} 05111 \rightarrow \mathrm{R} 051121 \rightarrow \\
\mathrm{R} 0511211 \rightarrow \mathrm{R} 05112111 \\
\text { (tujuh kali penelusuran) }\end{array}$ & $\begin{array}{l}\text { C0012: } \\
\text { Impingement ankle } \\
+\quad \text { Terapi } \\
\text { pengobatan }\end{array}$ & Cocok \\
\hline 13 & $\begin{array}{l}\text { Cedera Regio } \\
\text { kaki }\end{array}$ & $\begin{array}{lll}\text { R05 } \rightarrow \text { R051 } & \rightarrow \text { R0511 } \rightarrow \\
\text { R05111 } \rightarrow & \text { R051131 } \rightarrow \\
\text { R05113111 } & \text { (enam } & \text { kali } \\
\text { penelusuran) } & & \end{array}$ & $\begin{array}{l}\text { C0013: } \\
\text { Ankle instability + } \\
\text { Terapi pengobatan }\end{array}$ & Cocok \\
\hline 14 & $\begin{array}{l}\text { Cedera Regio } \\
\text { kaki }\end{array}$ & $\begin{array}{l}\text { R05 } \rightarrow \text { R054 } \rightarrow \text { R0541 } \rightarrow \\
\text { R05411 } \rightarrow \text { R054111 (lima kali } \\
\text { penelusuran) }\end{array}$ & $\begin{array}{lr}\text { C0014: } & \\
\text { Fraktur } & \text { Metatarsal } \\
+ & \text { Terapi } \\
\text { pengobatan } & \end{array}$ & Cocok \\
\hline 15 & $\begin{array}{l}\text { Cedera Regio } \\
\text { lutut }\end{array}$ & $\begin{array}{l}\text { R06 } \rightarrow \text { R061 } \rightarrow \text { R0611 } \rightarrow \\
\text { R06111 } \rightarrow \text { R061111 (lima kali } \\
\text { penelusuran) }\end{array}$ & $\begin{array}{l}\text { C0015: } \\
\text { Cedera Meniscus }+ \\
\text { Terapi pengobatan }\end{array}$ & Cocok \\
\hline 16 & $\begin{array}{l}\text { Cedera Regio } \\
\text { lutut }\end{array}$ & $\begin{array}{l}\text { R06 } \rightarrow \text { R062 } \rightarrow \text { R0621 (tiga } \\
\text { kali penelusuran) }\end{array}$ & $\begin{array}{l}\text { C0016: } \\
\text { Cedera Jumper's } \\
\text { knee / Patella } \\
\text { Tendinitis + Terapi } \\
\text { pengobatan }\end{array}$ & Cocok \\
\hline
\end{tabular}

\begin{tabular}{|c|c|c|c|c|}
\hline 17 & $\begin{array}{l}\text { Cedera Regio } \\
\text { lutut }\end{array}$ & $\begin{array}{l}\mathrm{R} 06 \rightarrow \mathrm{R} 063 \rightarrow \mathrm{R} 0631 \rightarrow \\
\mathrm{R} 06311 \rightarrow \mathrm{R} 063111 \rightarrow \\
\mathrm{R} 0631111 \rightarrow \mathrm{R} 06311111 \\
\text { (tujuh kali penelusuran) }\end{array}$ & $\begin{array}{l}\text { C0017: } \\
\text { Cedera Tendinitis } \\
\text { achilles / tendon } \\
\text { achilles }+ \text { Terapi } \\
\text { pengobatan }\end{array}$ & Cocok \\
\hline 18 & $\begin{array}{l}\text { Cedera Regio } \\
\text { lutut }\end{array}$ & $\begin{array}{l}\text { R06 } \rightarrow \text { R063 } \rightarrow \text { R0632 } \rightarrow \\
\text { R06321 } \rightarrow \text { R063211 (lima kali } \\
\text { penelusuran) }\end{array}$ & $\begin{array}{l}\text { C0018: } \\
\text { Kram pada betis / } \\
\text { ligamen }+ \text { Terapi } \\
\text { pengobatan }\end{array}$ & Cocok \\
\hline 19 & $\begin{array}{l}\text { Cedera Regio } \\
\text { lutut }\end{array}$ & $\begin{array}{l}\mathrm{R} 06 \rightarrow \mathrm{R} 064 \rightarrow \mathrm{R} 0641 \rightarrow \\
\mathrm{R} 06411 \rightarrow \mathrm{R} 064111 \rightarrow \\
\mathrm{R} 0641111 \rightarrow \mathrm{R} 06411111 \\
\text { (tujuh kali penelusuran) }\end{array}$ & $\begin{array}{l}\text { C0019: Iliotibial } \\
\text { band syndrome + } \\
\text { Terapi pengobatan }\end{array}$ & Cocok \\
\hline
\end{tabular}


Berdasarkan dari tabel hasil pengujian sistem, dapat di ambil kesimpulan bahwa kondisi yang dimasukkan (regio dan gejala) sudah sesuai dengan yang ada pada tabel pembentukan aturan / rule yang ada pada gambar 6.

\section{KESIMPULAN}

Berdasarkan penelitian yang dilakukan maka dapat ditarik kesimpulan yaitu sebagai berikut:

1. Pengujian sistem pakar dilakukan mulai dari pengujian sistem hingga ke pengujian rule.

2. Hasil penelusuran rule dimulai dari pemilihan regio, dilanjutkan dengan pemilihan gejala gejala yang tampak dan dirasa, setelah itu inferensi akan mengarahkan ke solusi.

3. Hasil pengujian rule cocok dengan pengetahuan yang didapat dari pakar.

4. Sistem pakar ini dapat digunakan untuk penanganan cedera olahraga bola basket.

\section{DAFTAR PUSTAKA}

[1]. Arhami, Muhammad. 2005. Konsep Dasar Sistem Pakar. Yogyakarta: Penerbit Andi.

[2]. Afifuddin. 2009. Rancang Bangun Sistem Pakar Untuk Mendiagnosa Penyakit Epilepsi (Ayan) Berbasis Website. Jurusan Teknik Informatika Fakultas Sains Dan Teknologi Universitas Islam Negeri (UIN) Maulana Malik Ibrahim Malang: Skripsi.

[3]. Kusrini. 2008. Aplikasi Sistem Pakar. Yogyakarta: Penerbit Andi.

[4]. Kusumadewi, Sri. 2003. Artificial Intelligence. Yogyakarta: Penerbit Andi.
[5]. Nasution, S. 2000. Metode Research. Jakarta: Penerbit Bumi Aksara.

[6]. Pressman, R. S. 2001. Software Engineering: A Practitioner's Approach. $5^{\text {th }}$ Edition. McGraw Hill

[7]. Sedarmayanti \& Hidayat, Syarifudin. 2011. Metodologi Penelitian. Bandung: Penerbit Mandar Maju.

[8]. Sutojo, Et Al .2011. Kecerdasan Buatan. Yogyakarta: Penerbit Andi.

[9]. Tim Penerbit ANDI. 2009. Pengembangan Sistem Pakar Menggunakan Visual Basic. Yogyakarta: Penerbit Andi.

[10]. Pijat olahraga bukan sembarang memijat.

http://id.olahraga.yahoo.com/news/s pt--pijat-olahraga-bukansembarang-memijat092955901.html. [Diakses tanggal28 desember 2012 